\title{
PADRÃO DE REPRODUÇÃO DO CAPITAL E CAPITALISMO DEPENDENTE NO BRASIL ATUAL
}

\author{
Luiz Filgueiras*
}

\begin{abstract}
A Teoria Marxista da Dependência (TMD), com o objetivo de entender as formas de reprodução do capital, nas distintas formações econômico-sociais, em diferentes períodos históricos do desenvolvimento capitalista, construiu o conceito de Padrão de Reprodução do Capital (PRC), apoiada na conhecida forma geral do ciclo do capital industrial, que é, também, a forma do ciclo do capital-dinheiro - conforme formulado por Marx. Este texto discute o alcance e o limite desse conceito para a compreensão da formação econômico-social brasileira contemporânea. Aponta que, embora ele contribua para o entendimento de formações econômico-sociais concretas, seu nível de abstração não permite perceber diferenças importantes existentes entre elas - em especial as latino-americanas. Como consequência, propõe, de forma complementar e em um nível menor de abstração, o conceito de Padrão de Desenvolvimento Capitalista (PDC), devidamente redefinido, e que se refere apenas a uma formação econômico-social singular (única pela sua história).

Palavras-chave: Teoria Marxista da Dependência. Padrão de Reprodução. América Latina. Padrão de Desenvolvimento. Brasil.
\end{abstract}

\section{INTRODUÇÃO}

Segundo a Teoria Marxista da Dependência (TMD), o capitalismo, desde sua gênese na Europa, já trazia, em si, uma tendência expansiva de incorporação e subordinação de todas as regióes do planeta à sua lógica, vindo a se constituir, já na segunda metade do século XIX, como um sistema mundial.

O impulso inicial dessa expansão, expresso no sistema colonial mercantilista (séculos XVI-XVIII), ganhou força com a Revolução Industrial, que colocou a Inglaterra na vanguarda desse movimento, dando origem (ao longo do século XIX) à primeira forma de divisão internacional do trabalho - que, de modo semelhante a todas as demais formas que se sucederam no tempo, foi inequivocamente assimétrica no que se refere ao poder, à inserção e ao lugar ocupado pelos distintos países na ordem capitalista internacional. Esse processo se aprofundou na virada do século XIX para o XX, quando o imperialismo moderno, da era do capital, se

* Universidade Federal da Bahia (UFBA). Faculdade de Economia.

Praça Treze de Maio, n. 06, Centro. Cep: 40.060-300. Salvador - Bahia - Brasil. luizmfil@gmail.com consolidou; e atingiu seu ápice nos últimos cinquenta anos, com o processo de mundialização do capital, sob o comando e a dominância do capital financeiro - o que lhe conferiu novas determinações (Chesnais, 1996).

Assim, a expansão do capitalismo se fez, desde sempre, de forma "desigual e combinada” (Löwy, 1998), através de ondas sucessivas de internacionalização do capital, que instituíram e reconfiguraram, algumas vezes, a divisão internacional do trabalho, primeiramente sob a hegemonia da Inglaterra e, posteriormente, dos EUA.

Por isso, a TMD, tal como as teorias do imperialismo, percebe o sistema capitalista mundial como uma ordem hierárquica, na qual uma pequena minoria de países (pioneiros do desenvolvimento capitalista) condiciona e subordina a grande maioria que, posteriormente, foi sendo incorporada. Distintamente das teorias do imperialismo, mas de forma complementar a elas, a TMD concebe o sistema capitalista mundial a partir da estrutura e da dinâmica econômico-social e política dos países subordinados, que, em última instância, têm seu desenvolvimento condicionado pelo 
desenvolvimento dos países imperialistas (Amaral, 2012).

Com essa perspectiva, a TMD identifica características específicas na forma como o capitalismo se desenvolveu nos países subordinados, dando origem ao capitalismo dependente, cuja reprodução está subsumida pela reprodução do capital nos países imperialistas. Portanto, ela advoga a existência de um capitalismo particular que, a despeito de ser regido pelas leis gerais de movimento do capital, apresenta leis específicas que redefinem a forma como as primeiras se realizam nas economias dependentes, condicionando o processo de reprodução do capital nelas existente. Em síntese, embora essas economias não sejam um simples reflexo das economias do centro, no longo prazo, sua dinâmica está delimitada pelo movimento de reprodução do capital imperialista e pela posição subordinada que ocupam na divisão internacional do trabalho (Marini, 1973a, 1973b).

Nessa reconstrução histórico-teórica do capitalismo dependente, situada em nível de abstração menor do que aquele no qual Marx construiu sua teoria do capital e do capitalismo - pois incorpora as relações internacionais entre distintos Estados nacionais, o mercado mundial e a competição intercapitalista -, a TMD elabora novos conceitos que, embora subsumidos aos conceitos construídos por Marx, estão associados à forma de funcionamento do capitalismo dependente (Osório, 2012a).

Esses novos conceitos - troca desigual, superexploração da força de trabalho, subimperialismo, etc. -, embora pertinentes à compreensão do capitalismo dependente, ainda se situam num nível de abstração elevado, ou seja, explicam as características mais gerais desse tipo de capitalismo, as quais o diferenciam do capitalismo dos países imperialistas, evidenciando que seu ciclo de reprodução do capital está condicionado pelo ciclo de reprodução do capital imperialista (Marini, 1979).

No entanto, a TMD deu um passo adiante ao reconhecer que a reprodução do capital pode assumir formas concretas diferentes ao longo da história do capitalismo e da divisão internacional do trabalho. Tais formas possuem relevância para se entender o modo de articulação internacional dos países, assim como o caráter de suas classes e frações de classe dominantes, suas relações com as classes trabalhadoras, as características do seu Estado, o bloco político no poder, a política econômica posta em prática pelos governos etc. No capitalismo dependente, regido pela troca desigual e a superexploração da força de trabalho, essas formas estão associadas a (e evidenciam) distintos modos como se concretiza a dependência em cada momento histórico.

Para dar conta das formas de reprodução do capital nas distintas formações econômico-sociais, em diferentes períodos históricos do desenvolvimento capitalista, a TMD construiu o conceito de Padrão de Reprodução do Capital (PRC), apoiada na conhecida forma geral do ciclo do capital industrial que é, também, a forma do ciclo do capital-dinheiro. A partir dele, pode-se indagar sobre as principais características que configuram certas regularidades na reprodução do capital em certo espaço territorial, em dado momento histórico - constituindo-se, assim, um padrão que nos informa como o capitalismo, em uma formação econômico-social concreta, se reproduz de modo articulado com a reprodução internacional do capital (Osório, 2012a).

O objetivo deste texto é o de discutir o alcance e o limite desse conceito para a compreensão da formação econômico-social brasileira contemporânea. Aponta-se que, embora ele contribua para o entendimento de formações econômico-sociais concretas, seu nível de abstração não permite perceber diferenças importantes existentes entre elas - em especial as latino-americanas. Como consequência, propõe-se aqui, de forma complementar e em um nível menor de abstração, o conceito de Padrão de Desenvolvimento Capitalista (PDC), devidamente redefinido, que se refere apenas a uma formação econômico-social singular (única pela sua história). 
Para isso, na seção que se segue a esta Introdução, é discutido e detalhado o conceito de PRC e seu uso por Osório (2012b) na definição de um Padrão Exportador de Especialização Produtiva que caracterizaria, hoje, todos os países da América Latina. Na sequência, discute-se e detalha-se o conceito de PDC e, posteriormente, a partir dele, analisam-se a estrutura e a dinâmica do capitalismo dependente brasileiro. Por fim, nas Considerações Finais, evidenciam-se, sinteticamente, os dilemas político-econômicos que demarcam, atualmente, o desenvolvimento do capitalismo dependente brasileiro.

\section{O CONCEITO DE PADRÃO DE RE- PRODUÇÃO DO CAPITAL ${ }^{1}$}

A TMD, em seus conceitos básicos, explica as particularidades do capitalismo dependente em geral, isto é, aquilo que ele tem de fundamental e que o diferencia do capitalismo imperialista. No entanto, ao longo do desenvolvimento do capitalismo como sistema mundial, a forma assumida pela dependência foi se transmutando conforme a reconfiguração do capitalismo nos países imperialistas e, por consequência, o surgimento de outros tipos de divisão internacional do trabalho.

Assim, a forma de reprodução do capital nas economias dependentes, por estar subordinada à reprodução do capital no plano internacional, também se modifica - com a constituição de padrões específicos de reprodução, que podem distinguir um mesmo país ao longo do tempo ou países distintos no mesmo momento histórico.

O conceito de PRC, pensado inicialmente por Marini (1982), e desenvolvido posteriormente por Osório (2012a), tem por função fazer a mediação entre as leis gerais do capitalismo e a dinâmica concreta da reprodução do capital

1 Essa seção tem como referência dois textos de Osório (2012a, 2012b) que tratam, respectivamente, do conceito de PRC e de sua utilização para a caracterização da América Latina na contemporaneidade.
- com a incorporação de mais determinações histórico-sociais para além daquelas necessárias à caracterização do capitalismo em geral. Ele estabelece "mediações entre os níveis mais abstratos e mais gerais de análise (modo de produção capitalista e sistema mundial capitalista) e os níveis menos abstratos ou históricos concretos (formação econômico-social e conjuntura)" (Osório, 2012a, p. 41). Objetiva “dar conta da forma como o capital se reproduz em um período histórico específico e em um espaço territorial determinado (no centro, na semiperiferia e na periferia), considerando as características de sua metamorfose na passagem pelas esferas da produção e da circulação" (Osório, 2012a, p. 40).

Portanto, esse conceito, ao permitir a passagem da análise para o plano da dinâmica histórico-concreta, possibilita a identificação de distintas formas de dependência e de ciclos de reprodução do capital no capitalismo dependente, assim como a hierarquização dos países dependentes como periféricos e semiperiféricos.

A partir do ciclo de reprodução do capital industrial, ou o ciclo do capital-dinheiro, representado por Marx como $D-M \ldots P \ldots M^{\prime}-D^{\prime}$, a TMD identifica e discute os elementos fundamentais, de natureza qualitativa, que determinam e dão substância ao conceito de PRC, que possibilitará a análise da dependência em situações singulares. Ele integra o processo de valorização com as formas materiais que este assume ao encarnar-se em determinados valores de uso: “... o valor de uso da valorização define as características do capitalismo que será gerado" (Osório, 2012a, p. 46).

Considerando-se $D-M$, a primeira fase da circulação, o capital-dinheiro $\underline{D}$, que dá partida ao processo de reprodução, coloca-se a questão do financiamento da acumulação e das características do investimento realizado: sua origem (capital estatal, apoiado em impostos diretos e indiretos ou através de empresas estatais, capital privado nacional e/ou capital estrangeiro), o modo de realizá-lo (lucros re- 
tidos, empréstimos, investimento estrangeiro direto, associações e/ou mercado de capitais) e a que setores se destina primordialmente. Nas circunstâncias atuais do capitalismo, é também importante observar a prevalência da dominância financeira no processo de acumulação.

A compra de mercadorias necessárias ao processo produtivo - isto é, meios de produção e força de trabalho, representados por $\underline{M}$ - nos remete à identificação da origem dos meios de produção (produzidos e comprados localmente e/ou importados) e à natureza da relação capital-trabalho e de sua regulação.

Nas economias dependentes, o ciclo do capital, nessa primeira fase da circulação, articula-se e subordina-se duplamente ao capital imperialista: os empréstimos e o investimento estrangeiro direto, assim como os meios de produção produzidos nos países imperialistas, são a forma concreta dessa articulação dependente.

A observação de $\underline{P}$ evidencia a natureza do processo produtivo: a tecnologia utilizada (origem, propriedade e como é adquirida) e as formas de organização do processo produção e de gestão e consumo da força de trabalho pelo capital (jornada de trabalho, produtividade e intensificação do trabalho), além do seu grau de qualificação.

No capitalismo dependente, a introdução $\infty$ de nova tecnologia, decorrente da presença de خें empresas estrangeiras, leva à diferenciação da ป estrutura produtiva e a um processo precoce de હ monopolização, além de se constituir em uma
Na segunda fase da circulação $\underline{M^{\prime}-D^{\prime}}$, de realização das mercadorias, $\underline{M}$ ' nos informa sobre o tipo de mercadoria (valor de uso) produzida: bens de capital e/ou bens de consumo (bens-salário e suntuários, duráveis e não duráveis), commodities industriais e agrícolas etc. e seu destino (mercado interno e/ou exportação). E $\underline{D}$ ' traz subjacente a forma de financiamento da realização das mercadorias (o sistema de crédito para a compra de meios de produção e o consumo das famílias).

Nas economias dependentes, a importância dos bens de consumo é maior, de forma contraditória com o que ocorre no processo de produção - apoiado na superexploração da força de trabalho. A estrutura concentrada da distribuição de renda limita o crescimento do mercado interno e provoca uma cisão ou separação entre produção e consumo de massa, implicando que parte importante da produção é para exportação.

Vê-se, portanto, que, embora esse ciclo de reprodução do capital, como valor, expresse como o processo de acumulação ocorre em qualquer economia capitalista, ele não tem a mesma natureza e o mesmo significado quando se consideram seus elementos materiais nos países imperialistas e nos países dependentes. Há distinções fundamentais sobre como a reprodução do capital se dá em cada um desses polos - que constituem o sistema capitalista mundial.

A subordinação do ciclo do capital dos países dependentes ao ciclo do capital dos países imperialistas se expressa em todas as fases do processo de reprodução do capital. Os vínculos de dependência se fazem presentes no financiamento e no investimento, nas importações de máquinas e equipamentos, na superexploração do trabalho, no uso da tecnologia importada e no pagamento de royalties e patentes, no tipo de mercadoria produzida e exportada, na remessa de juros e lucros etc. Em resumo: dependência tecnológica, comercial e financeira. Portanto, todo o ciclo de reprodução do capital, nos países dependentes, está 
subsumido à reprodução do capital imperialista - elemento externo, mas que se internaliza ao participar do ciclo da economia dependente - configurando-se numa forma de reprodução "partida”, na qual o consumo dos trabalhadores, na economia dependente, não se constitui em componente fundamental de realização das mercadorias (Marini, 1973a, 1973b, 1979).

Adicionalmente, faz-se necessária a consideração do Estado e das políticas econômicas que constituem o PRC, esfera que articula as suas dimensões econômica e política. Nesse âmbito, devem-se distinguir as frações do capital e os setores que estão no centro do PRC, evidenciando quem exerce a hegemonia em seu interior, além de identificar o propósito das políticas (fins, objetivos, metas etc.) e as práticas ou mecanismos de decisão (ações, meios, instrumentos, medidas, etc.), assim como os destinatários sociais das decisões (setores, classes, grupos etc.).

No capitalismo dependente, tanto o capital estrangeiro quanto o Estado são decisivos no processo de reprodução do capital, com o primeiro articulando diretamente com o exterior o ciclo da economia dependente e o segundo participando direta ou indiretamente de todas as fases do processo de acumulação e influenciando decisivamente a forma de articulação com o imperialismo e a trajetória da economia.

O processo de substituição de sucessivos PRC, acompanhado por revoluções tecnológicas, resulta em mudanças nas condições materiais de reprodução do capital: "mudanças nos setores ou ramos que serão eixos da acumulação, na organização do trabalho, nas condições técnicas, nas mercadorias produzidas, nos mercados para os quais será dirigida a produção, nos agentes que farão os investimentos, no tipo de associação com o capital estrangeiro, enfim, no conjunto ou em alguns dos principais estágios que marcam o rumo do ciclo do capital.” (Osório, 2012a, p. 70).

\section{Padrão exportador de especialização pro- dutiva}

A partir do conceito de PRC, Osório (2012b) identifica, na história da América Latina, três padrões, que se sucederam ao longo do tempo: o Padrão Agromineiro Exportador (até a segunda década do século XX), o Padrão Industrial (a partir da segunda metade dos anos 1930 até meados dos anos 1970) e, atualmente, o Padrão Exportador de Especialização Produtiva (de meados dos anos 1980 até o presente). Todos eles fazem parte do movimento mais geral do sistema capitalista mundial, que redefine a divisão internacional e o lugar e o sentido dos países dependentes nela.

O Padrão Exportador de Especialização Produtiva - que, segundo Osório, caracteriza hoje todos os países da América Latina - decorreu de grandes transformações no sistema capitalista mundial nas últimas quatro décadas, e tem os seguintes traços: 1) regresso a produções seletivas (bens secundários e/ou primários); 2) relocalização de segmentos produtivos; 3) novas organizações da produção/ toyotismo; 4) flexibilidade laboral e precariedade; 5) economias voltadas para a exportação; 6) drásticas reduções e segmentação do mercado interno; 7) fortes polarizações sociais; 8) aumento da exploração e da superexploração; e 9) níveis elevados de pobreza e indigência.

Apesar desses elementos comuns, Osório destaca que é necessário observar como esse padrão se desenvolve nas diversas formações econômico-sociais, em especial suas repercussões na estrutura de classes e no Estado, admitindo, portanto, "diferenças 'nacionais' dentro de um mesmo padrão de reprodução do capital" (Osório, 2012a, p. 80).

No entanto, a nosso ver, assumindo-se a análise do PRC a partir das características materiais do ciclo do capital - que permitem identificar as distintas classes e frações de classe e do capital, bem como suas respectivas posições no bloco no poder e o lugar do Estado no processo de acumulação, assim como diversos 
outros atributos que caracterizam um PRC -, não se pode generalizar, para todos os países da América Latina, um mesmo tipo de padrão, considerando-se a realidade atual, e muito menos quando se tem por referência o Padrão Industrial. Existem diferenças fundamentais não apenas na forma como esse último padrão se desenvolveu nesses países, mas no próprio padrão: a história factual informa que o processo de industrialização na América Latina se restringiu, fundamentalmente, a Brasil, México e Argentina; os demais tiveram uma ou outra indústria, o que não mostrou força suficiente para redefinir, mesmo que parcialmente, a dinâmica da economia "para dentro", com a diversificação e ampliação significativa de seus respectivos mercados internos.

O mesmo vale para a situação atual, em que pese o fato de estar ocorrendo um processo de especialização produtiva e desindustrialização da região, com efeitos em suas exportações. Pelo menos no caso do Brasil, essa especialização ocorre fundamentalmente em sua pauta exportadora, pois sua estrutura produtiva é ainda muito diversificada em todos os setores. Por isso, as transformações ocorridas não foram fortes o suficiente para redefinir, de novo, a dinâmica de sua economia "para fora": seu mercado interno ainda é o destino princiœ pal da produção, pois sua desindustrialização ড్ (e perda de participação de produtos manufaه turados em suas exportações) ainda é um feal., 2012).

Na verdade, a mundialização do capital não homogeneizou os PRC de todos os países da América Latina: há diferenças importantes entre suas respectivas estruturas produtivas (grau de complexidade), suas classes e frações de classes dominantes, o lugar e o papel do Estado no processo de acumulação e, em última instância, o lugar que ocupam na divisão internacional do trabalho: periferia ou semiperiferia. A própria possibilidade de reconhecimento da presença de um subimperialismo brasileiro na América do Sul tem como supos- to a existência dessas diferenças (Dossiê, 2013; Luce, 2011).

Ademais, acredito que uma maior precisão na qualificação do desenvolvimento capitalista dependente no Brasil exige nível de abstração menor do que aquele no qual se situa a noção de PRC - incorporando traços históricos que o diferenciam dos demais países da América Latina, o que nos leva ao uso do conceito de PDC.

\section{O CONCEITO DE PADRÃO DE DE- SENVOLVIMENTO CAPITALISTA ${ }^{2}$}

O conceito de Padrão de Reprodução do Capital (PRC) aponta para a discussão da estrutura e da dinâmica das economias dependentes, identificando cada forma concreta assumida pela dependência e como ela se realiza. No entanto, seu nível de abstração ainda carece de certas determinações histórico-sociais, o que limita o reconhecimento das diferenças existentes entre os países latino-americanos, apesar de unidos e assemelhados pelo caráter dependente de suas economias, e em especial a passagem da análise para o entendimento das sucessivas conjunturas.

Com o objetivo de sanar essa dificuldade, apresento o conceito de Padrão de Desenvolvimento Capitalista (PDC), devidamente redefinido como um conceito de caráter transdisciplinar, isto é, que sintetiza e expressa, ao mesmo tempo, as dimensões econômica, social e política de uma determinada formação econômico-social. Portanto, ele não se confunde com os conceitos de Padrão de Acumulação, próprio da Escola de Campinas, e de "Regime de Acumulação", proposto pela Escola da Regulação - ambos construídos também em um nível de abstração mais elevado e focando, essencialmente, a dimensão econômica do fenômeno (Almeida Filho, 1993).

\footnotetext{
${ }^{2}$ Essa seção é uma reprodução atualizada de formulações acerca do Modelo Liberal-Periférico desenvolvidas em trabalhos anteriores por Filgueiras (2005, 2006, 2013, 2017).
} 
Mas, da mesma forma que esses dois conceitos, o PDC se refere a um fenômeno histórico-estrutural de longo prazo, não se assemelhando, portanto, aos conceitos de "padrão ou regime de crescimento" e "regime de política macroeconômica" (Oreiro, 2011), "estratégia de crescimento ou desenvolvimento”, “convenções de desenvolvimento" (Erber, 2011) e "políticas de desenvolvimento ou políticas desenvolvimentistas", conceitos que dizem respeito e se circunscrevem a determinadas situações e características conjunturais que estão presentes, essencialmente, no plano da dinâmica econômica imediata e (ou) da ação dos agentes político-econômicos e do Estado, e que podem variar ao longo da vigência de um mesmo Padrão de Desenvolvimento Capitalista.

Em relação ao conceito de PRC da TMD, o de PDC aqui apresentado é construído em um nível de abstração menor, incorporando a história e as especificidades econômico-sociais e políticas dos distintos países. Isso significa dizer que o PDC é um conceito menos abrangente, uma singularidade que diz respeito apenas a uma determinada formação econômico-social, cujas características, em sua totalidade, não podem ser generalizadas para outros países. Adicionalmente, além de incorporar as dimensões econômica, social e política, ele permite articular estrutura e conjuntura, entendida esta como o modo como a estrutura se expressa em um dado momento. Isto é feito com a ajuda de outro conceito, o de Regime de Política Macroeconômica (RPM), que será esclarecido mais adiante, cuja existência e características sempre estarão subsumidas e condicionadas ao PDC existente.

De forma concisa, um Padrão de Desenvolvimento Capitalista é definido por um "conjunto de atributos - econômico-sociais e políticos - que estrutura, organiza e delimita a dinâmica do processo de acumulação de capital, e as relações econômico-sociais a ele subjacentes, existentes em determinado Estado (espaço) nacional durante certo período histórico" (Filgueiras, 2013).
A configuração do chamado Bloco Político no Poder (Poulantzas, 1977), num determinado período histórico, constitui seu atributo fundamental, que precede hierarquicamente todos os demais, porque, ao mesmo tempo em que os expressa sinteticamente, também os subsume, delimitando seu significado e alcance. Ele se situa na confluência entre estrutura e conjuntura, economia e política, Estado e mercado, sendo composto, em cada conjuntura, por determinadas classes e frações de classe que dominam o aparelho de Estado, direcionando-o de acordo com seus interesses - através da escolha e da colocação em prática de certas políticas econômico-sociais.

A classe ou fração que tem a capacidade de unificar e dirigir, política e ideologicamente, as demais, a partir de seus interesses específicos - transformados e reconhecidos como parte dos interesses gerais do conjunto do bloco -, mas também contemplando parcialmente outros interesses localizados em seu interior, assume a liderança e hegemonia do bloco no poder. Se essa hegemonia incorporar, marginal ou mais significativamente, interesses das classes subordinadas ou de algumas de suas frações - que não compõem o bloco no poder -, ela deixa de ser restrita a ele e se amplia, abarcando o conjunto da sociedade (Poulantzas, 1977).

Os demais atributos essenciais na definição de um PDC, sintetizados pelo bloco no poder, expressam, ao mesmo tempo, os interesses nele localizados, dando-lhes sentido e significado. Eles estão estreitamente relacionados e são compatíveis entre si, evidenciando que as diversas dimensões do processo de desenvolvimento capitalista, tal como ele se apresenta numa formação econômico-social específica, se reproduzem de modo articulado e concomitante. Esses atributos são apresentados a seguir.

1. A natureza e o tipo de regulação da relação entre capital e trabalho. Indicam o grau de assimetria (correlação de forças) existente entre as duas classes fundamentais de 
qualquer PDC (trabalhadores e capitalistas). Isso remete às formas de organização do processo de trabalho e de contratação da força de trabalho, que envolvem as representações corporativas (sindicatos e associações) de trabalhadores e capitalistas, bem como o Estado. Essa relação e o modo como o Estado participa dela permitem visualizar a natureza e o tipo de exploração da força de trabalho, a existência ou não de superexploração do trabalho. Além disso, remete à existência, ou não, de instituições e legislação reguladoras do mercado de trabalho e do consumo da força de trabalho pelo capital.

2. O caráter e a dinâmica das relações intercapitalistas. Apontam a força e a importância das distintas frações do capital e suas articulações no interior do Estado, bem como evidenciam as frações e setores do capital que "puxam" a economia (que se situam no centro da acumulação). Aqui se destacam os interesses específicos das distintas frações do capital, do ponto de vista setorial, do seu tamanho, da inserção internacional e da articulação com os capitais imperialistas. Esses são atributos decisivos para definir as frações do capital que participam do bloco no poder e, entre elas, quem exerce a hegemonia em seu interior.

3. O modo de inserção internacional do

$\infty$ país. Esse atributo evidencia o lugar ocupado : \} \text { os tipos de restrições externas existentes e, } ¿ como consequência, seu grau de vulnerabili\& ponto de vista produtivo, comercial, financeii ro e tecnológico - define e esclarece a nature-

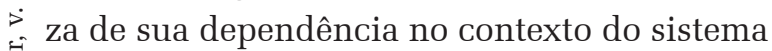
mundial capitalista.

4. O lugar e o modo como o Estado se articula com o processo de acumulação. Informa, desde logo, o caráter do Bloco no Poder e seus interesses, assim como o grau de autonomia relativa do Estado frente às distintas frações do capital. Aqui se destacam as políticas econômico-sociais e, em especial, o tipo de Regime de Política Macroeconômica; além das articulações e favorecimentos com relação a determinadas frações do capital. A participação do Estado, se diretamente, no plano da própria produção/financiamento e/ou de modo indireto, através da regulação, planejamento e indução do capital em geral, vai depender decisivamente da natureza do bloco no poder.

5. O processo de criação e incorporação do progresso técnico. Trata-se de um atributo essencial para definir o lugar ocupado pelo país no sistema capitalista mundial, pois a capacidade endógena de geração, adoção e difusão das inovações, bem como a existência, ou não, de um sistema nacional de inovações e de uma política industrial, comercial e tecnológica definem o caráter dependente ou imperialista do capitalismo. Numa economia dependente, isso se relaciona, estreitamente, com o espaço ocupado pelas empresas multinacionais na estrutura produtiva, a existência ou não de empresas estatais importantes e o tipo de articulação existente entre as distintas frações do capital e o imperialismo. Esse é um aspecto com implicações diretas sobre o tipo e o montante de excedente transferido para os países imperialistas.

6. O modo de financiamento da acumulação. Esse também é um aspecto incontornável para se definir o lugar ocupado pelo país no sistema mundial capitalista, pois evidencia a existência, ou não, de uma dependência financeira estrutural - que condiciona seu desenvolvimento e sua capacidade de colocar em prática políticas econômico-sociais. Isso se relaciona com a existência e a importância de instituições financeiras públicas e (ou) privadas nacionais, vis-à-vis o financiamento externo, bem como aos mecanismos de financiamento através dos mercados de capitais e de títulos e (ou) de empréstimos e endividamento.

7. A estrutura de propriedade e a distribuição de renda e da riqueza. Remetem ao lugar e ao grau de importância dos mercados 
interno e externo no processo de acumulação e crescimento, portanto, na dinâmica macroeconômica. Nesse âmbito, a existência e o conteúdo das políticas sociais são cruciais e colocam o Estado, mais uma vez, numa posição decisiva. Esse atributo explicita o grau de desigualdade e pobreza existente na sociedade. No capitalismo dependente, a concentração da propriedade fundiária, rural e urbana, implicou o desenvolvimento de grandes centros urbanos densamente povoados, fortemente segmentados do ponto de vista social e espacial, e com ampla presença de atividades informais (autônomas) precárias.

8. As formas de organização e representação política das distintas classes e frações de classes. Trata-se da presença e da força de movimentos sociais, sindicatos e partidos políticos e, em especial, a atuação e o grau de autonomia relativa do Estado frente às distintas classes e frações de classe.

Todos esses atributos que, conjuntamente, configuram um PDC remetem a uma questão central para a análise de sua estrutura e dinâmica, qual seja: a relação entre as dimensões nacional e internacional do processo de desenvolvimento, isto é, a importância relativa das circunstâncias internas e externas e a forma como elas se articulam e se relacionam na conformação desse padrão.

\section{O CASO BRASILEIRO 3}

O conceito de Padrão de Desenvolvimento Capitalista (Filgueiras, 2013) procura superar dois problemas que estão presentes no debate sobre a natureza e a dinâmica do capitalismo dependente brasileiro, tal como ele se configurou a partir dos anos 1990: de um lado, a separação (ou frágil articulação) entre economia e política, e, de outro, a não distinção e hierarquização entre as dimensões estrutural - as características mais permanentes e

${ }^{3}$ Essa seção reproduz, atualizando, análises desenvolvidas por Filgueiras $(2013,2017)$. enraizadas do PDC brasileiro - e conjuntural - a dinâmica macroeconômica de curto prazo.

Ao se fragmentar ou separar economia e política e não se distinguir estrutura de conjuntura, perde-se a visão de conjunto e dificulta-se o entendimento de como os interesses materiais, sociais e políticos - das classes e frações de classe - se cruzam e se determinam mutuamente, dando um sentido e uma tendência de longo prazo, em torno da qual ocorrem flutuações e inflexões (econômicas e políticas), mas que não têm capacidade de alterar esse padrão.

A superação do primeiro problema é dada pelo caráter transdisciplinar do próprio conceito de PDC, expresso na noção de bloco político no poder que, ao se situar na confluência entre economia e política e sintetizar os demais atributos econômico-sociais do PDC, consolida todas as dimensões da formação econômico-social. A solução do segundo problema exige a distinção clara entre o PDC existente e o RPM a ele subsumido, evidenciando como ambos se articulam na explicação da relação entre as tendências de longo prazo e as flutuações e inflexões (econômicas e políticas) conjunturais, com as respectivas políticas econômico-sociais momentaneamente adotadas.

A partir daí se pode enquadrar de forma precisa, e entender melhor, as continuidades e descontinuidades entre os governos que se sucederam no país a partir do início dos anos 1990, assim como os desempenhos distintos apresentados pela economia em cada um deles - com a manutenção da mesma forma de dependência, consubstanciada num mesmo PDC, que denomino de Padrão Liberal Periférico (PLP), mas com sucessivos e distintos RPM.

No plano mundial, o casamento político-prático entre o neoliberalismo e o capital financeiro (uma espécie de afinidade eletiva), possibilitado pela crise do capitalismo e do Estado de Bem-Estar nos anos 1970, deu origem a um programa político-econômico que pode ser resumido pelas seguintes características: privatizações, desregulação e liberalização. No 
entanto, esse programa e suas políticas concretas foram postos em prática de acordo com as especificidades das distintas formações econômico-sociais - singularizadas, sobretudo, pela sua condição de centro ou periferia, mas não apenas, pois tanto o centro quanto a periferia também não são homogêneos. Portanto, existe mais de um PDC associado ao neoliberalismo.

O PLP é a forma concreta específica assumida pela mundialização do capital e o neoliberalismo no Brasil a partir dos anos 1990, configurado a partir de rupturas fundamentais com relação à estrutura econômico-social anterior, própria do Padrão de Substituição de Importações vigente até então no país, e como resultado das disputas entre distintas frações de classes de sua burguesia, e entre estas e as classes trabalhadoras. No seu início, com o Governo Collor, cristalizou-se o que já era uma realidade no plano mundial, qual seja: uma nova hegemonia, desta feita comandada pelo capital financeiro, que subordinou a lógica produtiva a sua própria lógica volátil e de curto prazo. $\mathrm{Na}$ sequência, esse padrão se aprofundou durante os Governos de FHC e se legitimou. Momentaneamente, durante os Governos Lula e Dilma.

Isso significa dizer que, do ponto de vista do PLP, o caráter dos governos Collor, FHC e Temer, de um lado, e dos Governos Lula e $\infty$ Dilma de outro, se assemelham - seja promoసे vendo-o ativamente (comportamento dos pri¿ meiros), seja aceitando-o como irreversível, o limite do possível, e a ele se adaptando (no caso dos segundos). Contudo, quando se consideram os distintos RPM por eles adotados, esses governos se diferenciam na condução e administração, em cada conjuntura, desse \& padrão de desenvolvimento (Filgueiras, 2006; के Filgueiras; Gonçalves, 2007).

\section{O Padrão Liberal Periférico (PLP)}

As características fundamentais desse padrão, que o diferenciam do padrão de substituição de importações, são as seguintes (Fil- gueiras, 2013):

- A relação entre capital e trabalho teve sua assimetria aumentada a favor do primeiro, em razão da reestruturação produtiva e da abertura comercial, que implicaram o crescimento do desemprego estrutural, do trabalho informal, da terceirização e da precarização do trabalho em todas as suas dimensões. Como consequência, a capacidade de organização, mobilização e negociação dos sindicatos se reduziu dramaticamente.

- As relações intercapitalistas, em razão da abertura comercial-financeira e das privatizações, foram redefinidas, alterando-se a posição e a importância relativa das distintas frações do capital no processo de acumulação e na dinâmica macroeconômica: o capital financeiro (nacional e internacional) passou a ocupar posição dominante, deslocando a antiga hegemonia do capital industrial; o capital estatal perdeu relevância em favor do capital estrangeiro; e fortaleceram-se grandes grupos econômicos nacionais produtores e exportadores de commodities e o agronegócio.

- A inserção internacional do país na nova divisão internacional do trabalho se alterou para pior, aumentando sua vulnerabilidade externa estrutural. De um lado, a pauta de exportação do país se reprimarizou e se aprofundou o processo de desindustrialização iniciado ainda na década de 1980. De outro, cresceu dramaticamente sua dependência financeira, com o Estado se fragilizando e reduzindo fortemente sua capacidade de fazer política macroeconômica. Tudo isso decorreu da abertura comercial-financeira que também alimentou a desindustrialização do país e o crescimento da dívida pública - esta, como em outros países periféricos, transformou-se em plataforma de acumulação para o capital financeiro internacional.

- O papel e a importância do Estado, no processo de acumulação e na dinâmica macroeconômica, se alteraram - em virtude do processo de privatização e da abertura financeira. 
O Estado se fragilizou financeiramente e perdeu capacidade de financiar e regular a economia e de operacionalizar políticas macroeconômicas - apesar de seu resgate parcial e momentâneo nos governos Lula e Dilma.

- O modo de financiamento da acumulação se modificou radicalmente: investimentos estrangeiros diretos e empréstimos internacionais foram substituídos por investimentos estrangeiros nos mercados financeiros (Bolsa de Valores e Título da Dívida pública); e o financiamento estatal reduziu-se drasticamente - o que resultou em forte queda da taxa investimento em relação ao PIB.

- A estrutura de propriedade e a distribuição de renda (entre capital e trabalho) e da riqueza não se alteraram, apesar da redução momentânea da pobreza absoluta e de uma pequena melhora na distribuição da renda do trabalho durante os Governos Lula e Dilma. No total dos rendimentos das diversas frações do capital (lucros, juros e aluguéis), o capital financeiro aumentou sua participação na apropriação da mais-valia.

- O processo de criação e incorporação do progresso técnico: com o PLP, a capacidade do país nessa área, que já não era grande, reduziu-se drasticamente. A redução do financiamento público, as privatizações de empresas estatais e as incorporações (e fusões) de empresas nacionais pelo capital estrangeiro - associadas ao novo Regime de Propriedade Intelectual imposto pelos EUA no plano internacional, através da OMC - afastaram mais ainda o país da fronteira tecnológica e implicaram novas formas de transferência de renda para os países imperialistas. Mais recentemente, após o golpe que levou Temer à Presidência, a desestruturação da engenharia pesada nacional, a abertura das áreas do pré-sal ao capital estrangeiro, com a modificação do regime de exploração, e o desmonte da cadeia produtiva do petróleo, com a extinção da política de conteúdo nacional, fragilizaram ainda mais a capacidade de o país gerar e incorporar conhecimento e progresso técnico.
- As novas formas de organização e representação política das distintas classes e frações de classes, com a ampliação da esfera da sociedade civil, evidenciaram: 1) a incapacidade hegemônica da burguesia, o que levou à centralização e ao deslocamento do poder político real para fora das instituições políticas formais; 2) a importância da grande mídia corporativa na manipulação da esfera pública, como partido principal do capital em geral e do capital financeiro em particular (Souza, 2017); 3) mais recentemente, a "judicialização” da política e a deterioração da democracia formal, com a constituição, ainda em processo, de um Estado de exceção.

- Por fim, em razão de todas essas mudanças e, ao mesmo tempo, alimentando-as, constituiu-se um novo bloco no poder, sob a hegemonia absoluta, num primeiro momento, do capital financeiro e da burguesia cosmopolita, ${ }^{4}$ que passou a ditar as políticas fundamentais do Estado. Posteriormente, como condição de sobrevivência do próprio PLP, cresceu a importância do agronegócio e da indústria produtora de commodities, com o protagonismo da burguesia interna. ${ }^{5}$

Em suma, o padrão é liberal porque foi constituído a partir da abertura comercial e financeira, das privatizações e da desregulação da economia, com a clara hegemonia do capital financeiro - frente às demais frações do

${ }^{4}$ Os interesses da burguesia cosmopolita, assim como o seu modo de se reproduzir enquanto classe social, estão, desde sempre, fortemente associados e imbricados com os capitais estrangeiros, o capital financeiro e o imperialismo; com sua hegemonia político-ideológica se expressando, de forma inequívoca, no parlamento, no judiciário e nos grandes meios de comunicação.

${ }^{5}$ A grande burguesia interna, conceito cunhado por Nicolas Poulantzas $(1974,1977)$, não é sinônimo de burguesia nacional; diferentemente desta última, que já não existe no Brasil há décadas, não possui contradições incontornáveis com os capitais estrangeiros e o imperialismo, não é nacionalista; mas possui um espaço próprio de reprodução do capital que não passa necessariamente pela aliança com estes últimos - portanto, diferencia-se também da burguesia cosmopolita associada, política e objetivamente, ao imperialismo. Essa fração da burguesia brasileira está presente, e pode ser identificada, em vários ramos da indústria de transformação (têxtil, alimentos, bebidas, bens de capital, entre outros), na cadeia produtiva do petróleo, na construção civil pesada, na produção de commodities agrícolas e minerais, em segmentos do grande comércio varejista e do agronegócio. 
capital. E é periférico porque o neoliberalismo assume características específicas nos países capitalistas dependentes, as quais o tornam mais regressivo ainda quando comparado à sua agenda e à forma como é operacionalizado nos países capitalistas centrais.

Do ponto de vista da dinâmica macroeconômica, a característica fundamental desse padrão de desenvolvimento capitalista, que aprofundou estruturalmente a dependência tecnológica e financeira do país, se expressa em sua extrema instabilidade e sua grande vulnerabilidade externa estrutural - que acompanham, de perto, as alterações cíclicas da economia internacional. Esse padrão de desenvolvimento, com as características estruturais aqui mencionadas, iguala todos os governos brasileiros que se sucederam a partir de 1990.

No entanto, sua constituição passou por cinco momentos distintos, desde o começo da década de 1990.

1. Uma fase inicial de transição, bastante turbulenta, de ruptura com o MSI e implantação das primeiras ações concretas de natureza neoliberal, com o começo da hegemonia do capital financeiro (Governo Collor).

2. Uma fase de ampliação e consolidação da nova ordem econômico-social neoliberal, com a implementação do Plano Real e das reformas neoliberais, na qual se amplia e se consolida a hegemonia absoluta do capital financeiro no interior do bloco no poder ( $1^{\circ}$ Governo FHC).

3. Uma fase iniciada com o fim da âncora cambial e a adoção do tripé macroeconômico, na qual se fortalece o capital produtor-exportador de commodities - que amplia seu espaço no bloco no poder por ser vital para reduzir a instabilidade do modelo ( $2^{\circ}$ Governo FHC e $1^{\circ}$ Governo Lula).

4. Uma fase na qual se amplia a presença da burguesia interna no interior do bloco no poder, em articulação com o Estado, com esse último voltando a ter um papel ativo e mais direto no processo econômico e na arbitragem (autonomia relativa) dos interesses das distintas frações do capital $\left(2^{\circ}\right.$ governo Lula e governo Dilma).

5. O momento atual (governo Temer), de recomposição da hegemonia absoluta do capital financeiro e da burguesia cosmopolita, com uma nova onda de reformas neoliberais e a volta do tripé macroeconômico em sua versão rígida.

Ao longo dessas cinco fases, o PLP sofreu três inflexões que, além de reconfigurarem parcialmente o bloco no poder, provocaram alterações parciais e circunstanciais em sua dinâmica, em virtude da adoção de distintos $\mathrm{RPM},{ }^{6}$ diretamente relacionados às mudanças na conjuntura econômica internacional, quais sejam: a âncora cambial do Plano Real no primeiro governo FHC; o tripé macroeconômico (metas de inflação, superávit fiscal primário e câmbio flutuante) rígido no segundo Governo FHC e em parte do primeiro governo Lula; esse mesmo tripé, flexibilizado no segundo governo Lula e no primeiro governo Dilma; e, recentemente, a partir do segundo governo Dilma, e mais ainda do Governo Temer, retornou-se à aplicação rígida desse tripé.

\section{O PLP E SEUS RPM}

Esses distintos regimes, dependentes decisivamente da conjuntura internacional e que refletem prioridades e vantagens diferentes para as diversas frações do capital, sempre implicam alguma acomodação do bloco no poder. Portanto, são esses RPM que diferenciam os governos de FHC e Temer, de um lado, e os governos de Lula e Dilma, de outro - apesar de todos se assemelharem do ponto de vista do predomínio do Padrão de Desenvolvimento Capitalista Liberal Periférico, seja através de sua promoção ativa (comportamento dos primeiros), seja de forma adaptativa passiva (os segundos).

${ }^{6}$ Um Regime de Política Macroeconômica se define pelos seus objetivos, metas operacionais e instrumentos utilizados; de acordo com o tipo de regime de crescimento a ser perseguido e consolidado: "puxado" pelo salário, pelo investimento ou pelas exportações. 
Desse modo, a hegemonia do capital financeiro no Brasil foi incontestável até o início do segundo Governo FHC (1999-2002), quando a política econômica do Plano Real, centrada na chamada "âncora cambial", levou à sobrevalorização do real e a uma crise cambial arrasadora, que obrigou à mudança dessa política. A partir daí o bloco no poder passou por uma acomodação em sua correlação de forças internas, com o fortalecimento de frações do capital exportador - indústria extrativa mineral e agronegócio -, condição crucial para redução da vulnerabilidade externa conjuntural do país. Mais adiante, já na virada do primeiro para o segundo Governo Lula, o bloco no poder sofreu uma segunda acomodação: cresceram em importância outras frações do capital, como as grandes empreiteiras e as grandes redes de comércio varejista - na esteira da retomada dos investimentos do Estado e de uma política econômica de estímulo ao consumo. Por fim, a partir do governo Temer, o capital financeiro e a burguesia cosmopolita recuperam a hegemonia absoluta no interior do bloco no poder.

Durante todo esse período, a hegemonia do capital financeiro nunca foi questionada, muito menos superada - apesar de ele ter sido obrigado a partilhar o poder com outras frações do capital, o que se expressou durante o segundo Governo Lula na flexibilização do tripé de política macroeconômica.

O boom econômico internacional nos anos 2000, só interrompido pela crise mundial deflagrada em 2008, permitiu, em razão da redução da vulnerabilidade externa conjuntural do país, a flexibilização (relaxamento) do tripé macroeconômico. Essa flexibilização, associada a outras políticas - Bolsa Família, aumento real do salário mínimo e um programa de habitação popular -, teve como consequência a elevação das taxas de crescimento do país e a redução das taxas de desemprego, assim como a diminuição da pobreza absoluta e uma pequena redução da concentração de renda no interior dos rendimentos do trabalho (Druck; Filgueiras, 2007).
A melhora desses e de outros indicadores veio acompanhada de uma inflexão do bloco no poder, na qual o capital financeiro sofreu um deslocamento em sua hegemonia absoluta, tendo de admitir o crescimento da influência de outras frações do capital na condução do Estado: o agronegócio, o capital produtor e exportador de commodities, as grandes empreiteiras e os grandes grupos do comércio varejista. Em suma, a chamada burguesia interna passou a ser objeto prioritário das políticas do Estado, em especial através do BNDES, do Banco do Brasil, da Caixa Econômica Federal e da Petrobrás. E tudo isso, com apoio em um maior protagonismo do Estado, foi feito sem atingir os interesses fundamentais do capital financeiro.

Esse momento conjuntural específico do PLP, produto de uma conjuntura internacional favorável e caracterizado por um regime de política macroeconômica que flexibilizou o "tripé", reacomodou as distintas frações do capital no interior do bloco no poder e permitiu incorporar, via mercado e de forma passiva, determinadas demandas populares. Essa circunstância conjuntural - que trouxe para o primeiro plano a constituição de uma aliança informal entre os interesses da burguesia interna e de segmentos da classe trabalhadora, propiciando a incorporação de algumas de suas demandas - foi interpretada, no calor da luta política, como um novo padrão de desenvolvimento, denominado de neodesenvolvimentismo (desenvolvimento com distribuição de renda e inclusão social) - que teria superado o Padrão Liberal Periférico característico dos Governos Collor e FHC (Barbosa; Souza, 2010). No entanto, a crise mundial do capitalismo deflagrada em 2008, com a consequente piora da conjuntura internacional, bem como o impeachment de Dilma e a retomada das contrarreformas neoliberais a partir daí desmentiram categoricamente essa ilusão. A crise incialmente dificultou e, depois, acabou por inviabilizar a continuação da flexibilização do tripé macroeconômico e a compatibilização 
dos interesses divergentes das distintas frações do capital e dos distintos setores populares.

$\mathrm{Na}$ esteira da persistência da crise internacional, o capital financeiro voltou a ter protagonismo mais ativo e exigiu o retorno da aplicação rígida do tripé macroeconômico como política econômica permanente de Estado. Abriu-se, então, uma disputa entre a burguesia cosmopolita e a burguesia interna pelo comando do Estado e de suas políticas, que veio a culminar com a derrota da segunda, impulsionada pelo golpe de Estado operacionalizado através do impeachment da Presidente e o retorno, já no Governo Temer, da agenda neoliberal em sua face mais radical.

\section{CONSIDERAÇÕES FINAIS}

$\mathrm{O}$ argumento fundamental apresentado neste texto é o de que o conceito de PRC, próprio da TMD, é insuficiente para dar conta das especificidades das distintas formações econômico-sociais capitalistas, em especial os capitalismos dependentes dos países latino-americanos. Daí a necessidade de uma análise com menor nível de abstração.

No que tange ao Brasil, acredita-se que o padrão exportador de especialização produtiva $\infty$ não expressa o modo de reprodução do capital política macroeconômica, adotados desde o início dos anos 1990, e de algumas inflexões ocorridas no bloco no poder, não se alteraram as características essenciais do PLP - forma concreta de expressão da doutrina e do programa neoliberal no Brasil.

Do ponto de vista estrutural, o PLP atualizou, e até piorou, algumas das características mais marcantes da formação econômico-social brasileira: a dependência externa tecnológica e financeira, com grande transferência de renda para fora do país; a inserção passiva e subalterna na divisão internacional do trabalho; a enorme concentração de renda e desigualdade social; o rebaixamento permanente do estatuto do trabalhador; e a apropriação do público (e do Estado) pelo privado (grande capital).

A trajetória do PLP forjou um consenso básico entre as distintas frações do capital, apesar das diferentes posições que ocupam no processo de acumulação capitalista (Filgueiras, 2017): 1- a abertura comercial e financeira da economia, com a sua consequente internacionalização, é condição obrigatória de inserção do país na nova ordem dominada pelo capital financeiro; 2) a dominância desse capital e o processo de financeirização da economia não podem ser questionados; a adaptação à nova ordem capitalista é o único caminho possível; 3) a continuação do processo de privatização - com a consequente redução do Estado no âmbito produtivo - deve continuar, tanto por meio dos novos investimentos na área de infraestrutura do país, quanto da venda das empresas públicas ainda existentes; 4) a desregulamentação do mercado de trabalho deve ser aprofundada, na linha da "prevalência do negociado sobre o legislado"; 5) as reformas neoliberais, e a redução de direitos sociais, são pré-condições para a redução do "custo Brasil" e o desenvolvimento do capitalismo brasileiro. Desse modo, não há qualquer possibilidade de construção política de um projeto nacional de caráter capitalista vir a ser concebido e dirigido por qualquer fração da burguesia brasileira, em virtude de sua absoluta 
incapacidade de expressar e incorporar, econômica e politicamente, interesses diferenciados do conjunto da sociedade brasileira e conviver com uma melhor distribuição de renda: a superexploração do trabalho está entranhada em seu ethos de classe e na subjetividade de seus integrantes.

Recebido para publicação em 03 de abril de 2018 Aceito em 04 de maio de 2018

\section{REFERÊNCIAS}

ALMEIDA FILHO, N. Padrões de acumulação, industrialização e desenvolvimento: elementos para uma atualização conceitual. In: Economia Ensaios, Uberlândia, v.8, n. 1, p. 3-24, dez. 1993

AMARAL, M. S. Teorias do imperialismo e da dependência: a atualização necessária ante a financeirização do capitalismo. 2012. 147 p. Tese (Doutorado em Economia) - Programa de Pós-Graduação em Economia da FEA-USP.

BARBOSA, N.; SOUZA, J. A. P. de. A inflexão do governo Lula: política econômica, crescimento e distribuição de renda. In: SADER, E.; GARCIA, M. A. (Orgs.) Brasil entre o passado e o futuro. São Paulo: Boitempo Editorial, 2010. p. $57-110$.

CHESNAIS, F. A mundialização do capital. São Paulo: Xamã, 1996. 199p.

DOSSIÊ. Imperialismo brasileiro? Uma polêmica teórica e política. São Paulo: UNESP, 2013. In: Crítica Marxista, n. 36, p. 101-151.

DRUCK, G.; FILGUEIRAS, L. Política social focalizada e ajuste fiscal: as duas faces do Governo Lula. Revista Katálysi, Florianópolis, Departamento de Serviço Social da UFSC, v. 10, n. 1, p. 24-34, jan./jun. 2007.

ERBER, F. As convenções de desenvolvimento no governo Lula: um ensaio de economia política. Revista de Economia Política, São Paulo, v. 31, n. 1, p.31-55, jan./mar. 2011.

FILGUEIRAS, L. Os governos do partido dos trabalhadores: padrão de desenvolvimento capitalista e regimes de política macroeconômica. FE-UFBA, 2017. 28p. (mimeo).

. A natureza do atual padrão de desenvolvimento brasileiro e o processo de desindustrialização. In: CASTRO, I. S. B. Novas interpretações desenvolvimentistas. Rio de Janeiro: E-papers: Centro Internacional Celso Furtado, 2013. p. 371-450.

O Neoliberalismo no Brasil: estrutura, dinâmica e ajuste do Modelo Econômico. In: BASUALDO, B.; ARCEO, E. (Orgs.) Neoliberalismo y sectores dominantes - tendencias globales y experiencias nacionales. Buenos Aires: CLACSO, 2006. p. 179-206. (Colección Grupos de Trabajo).

. Projeto político e modelo econômico neoliberal no Brasil: implantação, evolução, estrutura e dinâmica. FEUFBA, 2005. 57p. (mimeo)

FILGUEIRAS, L. et al. O desenvolvimento econômico recente: desindustrialização, reprimarização e doença holandesa. Desenbahia, Bahia, v. 9, n. 17, p. 119-154, set. 2012.

FILGUEIRAS, L.; GONCALVES, R. A economia política do Governo Lula. Rio de Janeiro: Contraponto, 2007. 254 p.
LÖWY, M. A teoria do desenvolvimento desigual e combinado. Revista outubro, n. 1, p. 73-80, 1998. Disponível em: http://www.revistaoutubro.com.br/ edicoes/01/out01_06.pdf. Acesso em: 01. 06. 2018.

LUCE, M. S. A teoria do subimperialismo em Ruy Mauro Marini: contradiç̃es do capitalismo dependente e a questão do padrão de reprodução do capital. A história de uma categoria. 2011. 225 p. Tese (Doutorado em História)Programa de Pós-Graduação em História da UFRGS

MARINI, R. M. O ciclo do capital na economia dependente. 1979. In: FERREIRA. C., OSORIO, J., LUCE M. (Orgs.) Padrão de reprodução do capital. São Paulo, SP: Boitempo, 2012. cap. 1. p. 21-35.

MARINI, R. M. Dialética da Dependência. 1973a. In: TRASPADINI, R.; STEDILE, J. P. (Orgs.) Ruy Mauro Marini - Vida e obra. $2^{a}$ edicão. São Paulo-SP: Editora Expressão Popular, 2011. p. 131-172.

Sobre a dialética da dependência. 1973b. In: TRASPADINI, R.; STEDILE, J. P. (Orgs.) Ruv Mauro Marini - Vida e obra. $2^{\mathrm{a}}$ edição. São Paulo-SP: Editora Expressão Popular, 2011. p. 173-185.

MARINI, R. M. Sobre elpatrón de reproduccióndel capital em Chile. Cuadernos de Cidamo, Cidade do México, n. 76 , 1982

OREIRO, J. L. Crescimento e regimes de política macroeconômica: teoria e aplicação ao caso brasileiro (1999-2011). In: $8^{\circ}$ FÓRUM DE ECONOMIA DE SÃO PAULO. São Paulo: FGV, 2011

OSÓRIO, J. América Latina: o novo padrão exportador de especialização produtiva - estudo de cinco economias da região. In: FERREIRA, C.; OSÓRIO, J.; LUCE, M. (Orgs.) Padrão de reprodução do capital. São Paulo, SP: Boitempo, 2012b. cap. 4. p. 103-133.

Padrão de reprodução do capital: uma proposta teórica. In: FERREIRA, C.; OSORIO, J.; LUCE, M. (Orgs.) Padrão de reprodução do capital. São Paulo, SP: Boitempo, 2012a. cap. 2. p. 37-86.

POULANTZAS, N. As classes sociais no capitalismo de hoje. RJ: Zahar, 1974. 368p.

. Poder político e classes sociais. São Paulo: Martins Fontes, 1977. 354p.

SOUZA, J. A elite do atraso: da escravidão à lava jato. Rio de Janeiro: Leya, 2017. 240 p. 


\section{CAPITAL AND CAPITALISM REPRODUCTION STANDARD DEPENDENT IN CURRENT BRAZIL}

\author{
Luiz Filgueiras
}

The Marxist Theory of Dependency (MTD), with the aim of understanding the ways in which capital is reproduced in different economic and social formations in different historical periods of capitalist development, constructed the concept of Capital Reproduction Pattern (CRP), supported in the known general form of the cycle of industrial capital, which is also the form of the moneycapital cycle - as formulated by Marx. This text discusses the scope and limit of this concept for the understanding of contemporary Brazilian socioeconomic formation. It is pointed out that, although it contributes to the understanding of concrete socio-economic formations, its level of abstraction does not allow to perceive important differences existing between them - especially the Latin American ones. As a consequence, it is proposed, in a complementary way and in a lower level of abstraction, the concept of a Capitalist Development Pattern (CDP), duly redefined, and which refers only to a unique socio-economic formation (unique in its history).

KEYwORDS: Marxist Theory of Dependence. Dependent Capitalism. Capital Reproduction Pattern. Capitalist Development Pattern. Brazilian Economy.

\section{CAPITAL ET NORME DE REPRODUCTION DU CAPITALISME DEPENDANT DU BRESIL ACTUEL}

\author{
Luiz Filgueiras
}

La Théorie Marxiste de la Dépendance (TMD), dans le but de comprendre la façon dont le capital est reproduit dans différentes formations économiques et sociales dans différentes périodes historiques du développement capitaliste, a construit le concept de Modèle de Reproduction du Capital (MRC), soutenu dans la forme générale connue du cycle du capital industriel, qui est aussi la forme du cycle du capital-argent - tel que formulé par Marx. Ce texte discute la portée et la limite de ce concept pour la compréhension de la formation socio-économique brésilienne contemporaine. Il est souligné que, bien qu'il contribue à la compréhension de formations socio-économiques concrètes, son niveau d'abstraction ne permet pas de percevoir les différences importantes existant entre eux - en particulier les latino-américains. En conséquence il est proposé, d'une manière complémentaire et dans un niveau d'abstraction inférieur, le concept de Modèle de Développement Capitaliste (MDC), dûment redéfini, qui se réfère uniquement à une formation économique et sociale singulière (unique pour son histoire).

Mots-CLÉs: Théorie Marxiste de la Dépendance. Capitalisme Dépendant. Modèle de Reproduction de Capital. Modèle de Développement Capitaliste. Économie brésilienne.

Luiz Filgueiras - Doutor em Teoria Econômica. Pós-Doutorado em Economia pela Universidade Paris 13. Professor Titular da Universidade Federal da Bahia. Atua na área de Economia Política e Economia Brasileira Contemporânea, com ênfase principalmente nos seguintes temas: padrões de acumulação e de desenvolvimento, inserção internacional, política econômica, planos de estabilização, crise e padrões de desenvolvimento, políticas sociais e mercado de trabalho, reestruturação produtiva e emprego. Publicações recentes: Economia política versus economia positiva: proposta de um antimanual de introdução à economia. Revista da Sociedade Brasileira de Economia Política, v. 50, p. 142-164, 2018; Ajuste fiscal e as universidades públicas brasileiras: a nova investida do banco mundial. Caderno do CEAS, v. 242, p. 603-634, 2017; Economia, política e o bloco no poder no Brasil. Bahia Análise \& Dados, v. 27, p. 147-177, 2017; História do Plano Real. Ed. Boitempo, 2000, 2016. 